\title{
CHEMICAL INTERACTIONS TO CLEANUP HIGHLY POLLUTED AUTOMOBILE SERVICE STATION WASTEWATER BY BIOADSORPTION-COAGULATION-FLOCCULATION
}

\author{
Carlos Banchon', Alexandra Castillo², Paola Posligua² \\ 1 Department of Environmental Engineering, Universidad Agraria del Ecuador, Av. 25 de Julio y Pio Jaramillo, \\ 59304, Guayaquil (Guayas), Ecuador, e-mail: cbanchon@uagraria.edu.ec \\ 2 Universidad de Las Américas (UDLA), Environmental Engineering, Av. de los Granados \& J. Queri, 59302, \\ Quito, Ecuador, e-mail: acastillo@udlanet.ec, p.posligua@udlanet.ec
}

Received: 2016.09.01

Accepted: 2016.10.23

Published: 2017.01.01

\begin{abstract}
The present study addresses an ecofriendly solution to treat automobile service stations effluents with high concentrations of oily substances, surfactants, organic matter and heavy metals. Bioadsorption using sawdust from pine trees, sugar cane bagasse and coconut coir without any chemical modification removed colloidal contamination up to $70 \%$. Polyaluminium chloride, ferric chloride and polyacrylamide were applied to remove dissolved and colloidal pollutants under saline conditions without change of initial $\mathrm{pH}$. Both bioadsorption and coagulation-flocculation removed up to $97.8 \%$ of BOD, COD, surfactants and heavy metals at a saline concentration of $1.5 \% \mathrm{NaCl}$. The increase of ionic strength promoted a high sludge index and a representative cost saving in chemicals consumption of almost $70 \%$. High levels of pollution removal with the minimal use of chemicals is herein presented.
\end{abstract}

Keywords: adsorption; agricultural wastes; bagasse; coconut coir; sawdust; sludge

\section{INTRODUCTION}

In the last ten years, worldwide automobile sales grew from 66 to 89 million units [OICA, 2016]. As a result, automobile service stations consume uncontrolled amounts of water. It has been estimated that washing a single vehicle involves volumes between $100-600 \mathrm{~L}$ of water which contributes to approximately 15 million liters of wastewater annually [Abdelmoez et al. 2013; Lau et al. 2013; Mohamed et al., 2014]. The wastewater from this activity contains lubricating oils, surfactants, sulfides and heavy metals such as cadmium, lead, arsenic, iron, zinc, chromium, aluminum, nickel, vanadium and copper [Kumar et al. 2014; Mohamed et al. 2014]. This concentration of oil has been reported to levels close to $3000 \mathrm{mg} \cdot \mathrm{L}^{-1}$ [Zhao et al. 2014]. Indeed, this discharge negatively affects natural resources, since it was recorded that until 2011224 thousand tons of oil were discharged into the environment without any treatment [Sabir 2015]. Thus, the study of remediation and pollution effects of effluents from auto service stations is of high interest to society.

Remediation of oil and detergent wastewater from automobile service stations is performed by different methods: (i) physical methods like adsorption, filtration or mechanical remotion; (ii) chemical methods like dispersion, oxidation, coagulation, combustion or solidification; and (iii) biological methods like biodegradation [Shadizadeh et al. 2014]. However, many of these technologies present many problems due to high costs or because of emulsion formation or microdrops clotting [Sokolovic et al. 1992]. Nevertheless, adsorption is the less expensive and has minimal effects on the environment. To remove oils and heavy metals minerals such as alumina, clay, activated carbon, zeolite, ash, bentonite and agro wastes like coffee, banana, mango, orange, peanuts, rice and coconut and sugar cane, as well 
as hydrogels can be utilized [Abdeen \& Moustafa 2016; Barakat 2011; Bhatnagar \& Sillanpää 2010]. Coconut coir, rice husks, bagasse and pine sawdust, both without pretreatment or as activated carbon, have been used as adsorbents for the removal of heavy metals and azo dyes at acid $\mathrm{pH}$ [Abdel et al. 2011; Bhatnagar \& Sillanpää 2010].

Mixtures of surfactants and lubricants tend to form emulsions and consequently they are adsorbed by natural sediments. This leads to their accumulation in the background sediments of natural waterborne. Therefore, the objective of this study was to evaluate the minimal chemical conditions to remediate automobile service station wastewater by bioadsorption and coagulation-flocculation using cane bagasse, coconut coir and sawdust.

\section{MATERIAL AND METHODS}

\section{Water characterization}

Wastewater samples were taken from a local automobile service station in Quito, Ecuador. The total dissolved solids (TDS), electrical conductivity (EC), $\mathrm{pH}$, and salinity $(\% \mathrm{NaCl})$ were measured with multiparameter electrodes (HI 2550 Hanna, USA). The turbidity (in nephelometric units, NTU) and absorbance were measured by a spectrophotometer UV-Vis Nanocolor II (Macherey-Nagel, Germany). The chemical oxygen demand (COD), concentration of cationic (CT), anionic (AT) and non-ionic (NIT) tensoactives were determined at $620 \mathrm{~nm}$ (Macherey-Nagel, Germany). The biological oxygen demand (BOD) was measured by respirometry (WTW, Germany). The concentration of heavy metals (aluminum, copper, chromium and lead) was determined by flame atomic absorption methods according to APHA 3111-D and 3111-B. Oils and greases were also analyzed using the standard method 5520-B.

\section{Bioadsorption}

Sawdust from pine trees, sugar cane bagasse and coconut coir fibers were used as natural adsorbent material (bioadsorbent) without any chemical modification. The materials were dried at $60{ }^{\circ} \mathrm{C}$ for $1 \mathrm{~h}$ and later crushed, sieved and classified according to their particle size. Each dose of bioadsorbent was weighed and added to $500 \mathrm{~mL}$ of wastewater in a jar test equipment (Velp scientific, Spain) where the mixing time was $20 \mathrm{~min}$ at
$150 \mathrm{rpm}$. Then, the particles were left immobile for 10 minutes and finally removed by a $0.20 \mathrm{~mm}$ filter. The filtrate was used for coagulation-flocculation processes. It should be noted that oil and surfactants from the wastewater formed an emulsion; therefore, the initial and final turbidity were used as an index to measure colloids removal (suspended solids). Turbidity remotion in percent $(\% R)$ was calculated by the difference between initial $\left(T_{o}\right)$ and final turbidity $\left(T_{f}\right)$ according to:

$$
\% R=\frac{T_{f}-T_{o}}{T_{o}} * 100
$$

\section{Coagulation-flocculation}

Polyaluminium chloride (PAC) and ferric chloride hexahydrate were the coagulants provided by Dicomsa (Ecuador) and Fisher Scientific (USA) respectively. Flocculant was polyacrylamide (PA) at $0.1 \% \mathrm{w} / \mathrm{v}$. In Table 1, the operating conditions are detailed. Before and after coagulation-flocculation, the concentration of total dissolved solids (TDS), suspended solids (SS) in $\mathrm{mg} \cdot \mathrm{L}^{-1}$ and sludge index (IL) in $\mathrm{g} \cdot \mathrm{L}^{-1}$ were determined by standard methods $2540-\mathrm{B}, 2540-\mathrm{C}$ and 2540-D respectively.

\section{Experimental design}

Completely randomized factorial designs (CRFD) were applied in this work according to the network strategy which is shown in Figure 1, where all treatments are interconnected from previous experimentation. In order to achieve the optimal dosing concentration of chemicals, factors $(k)$ and levels $(l)$ were combined in treatments which are summarized in Table 2.

\section{RESULTS AND DISCUSSION}

\section{Effect of bioadsorbent dosages and particle size}

The treatments using bioadsorbents were a combination of dosing concentrations and par-

Table 1. Jar test conditions

\begin{tabular}{|l|c|c|}
\hline \multicolumn{1}{|c|}{ Operation } & Time range $(\mathrm{min})$ & Mixing $(\mathrm{rpm})$ \\
\hline Coagulant addition & $0-3$ & 200 \\
\hline Flocculant addition & $3-5$ & 200 \\
\hline Flocculation & $5-8$ & 40 \\
\hline Sedimentation & $8-20$ & 0 \\
\hline
\end{tabular}


Table 2. Operational conditions of experimental designs

\begin{tabular}{|c|l|c|c|c|}
\hline Treatment & \multicolumn{1}{|c|}{ Factor $(\mathrm{x})$} & Low level $(-1)$ & Zero level $(0)$ & High level $(+1)$ \\
\hline \multirow{2}{*}{ A } & Bioadsorbent dose $\left(\mathrm{g} \cdot \mathrm{L}^{-1}\right)$ & 0.6 & 1.0 & 3.0 \\
& Bioadsorbent particle size $(\mathrm{mm})$ & 0.3 & 0.5 & 1.5 \\
\hline \multirow{3}{*}{ B } & Type of coagulant & $\mathrm{FeCl}_{3}$ & - & PAC \\
& Coagulant conc. $(\%)$ & 5 & 10 & 15 \\
\hline \multirow{2}{*}{ C } & Coagulant dose $\left(\mathrm{g} \cdot \mathrm{L}^{-1}\right)$ & 0.2 & - & 1.0 \\
\hline \multirow{2}{*}{$\mathrm{D}$} & 5\% PAC dose $\left(\mathrm{g} \cdot \mathrm{L}^{-1}\right)$ & 0.2 & - & 1.6 \\
\hline & PA dose $(\mathrm{g} \cdot \mathrm{L}-1)$ & 0.6 & - & $\mathrm{FeCl}_{3}$ \\
\hline
\end{tabular}

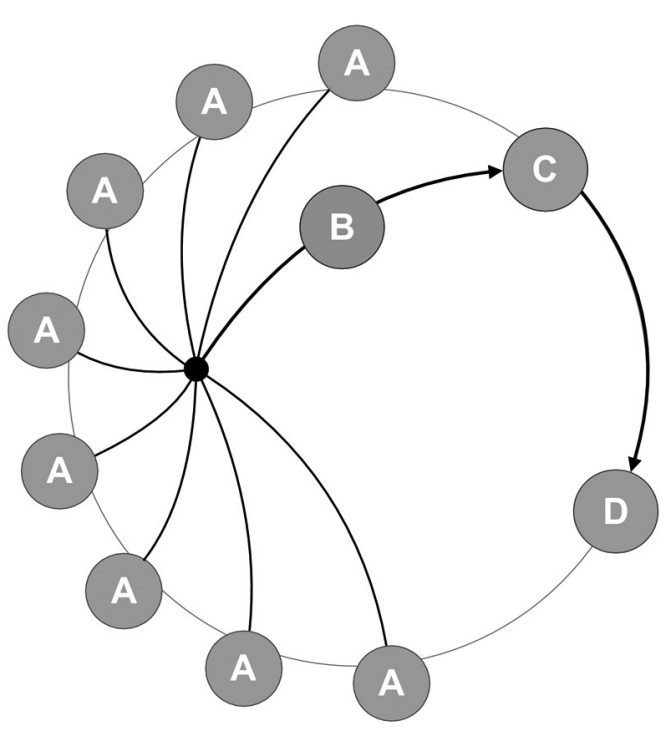

Figure 1. Network connection among all experimental designs. Treatments: (A) dose and particle size of three bioadsorbents, (B) experiments with two types of coagulants, (C) experiments to find coagulant and flocculant dosing concentration after bioadsorption and (D) effect of salinity on turbidity removal ticle size on turbidity removal (Fig. 2). Approx. $75 \%$ of colloidal suspension was removed by cane bagasse, $50 \%$ by sawdust and $40 \%$ by coconut coir respectively. In all treatments, although not shown in Figure 2, $\mathrm{pH}$ was reduced from 8.5 to 7.7 . Electrical conductivity changed from $496 \mu \mathrm{S} . \mathrm{cm}^{-1}$ to $605.2 \mu \mathrm{S} \cdot \mathrm{cm}^{-1}$ when sawdust was used, to $296.6 \mu \mathrm{S} \cdot \mathrm{cm}^{-1}$ for cane bagasse and to $494.0 \mu \mathrm{S} \cdot \mathrm{cm}^{-1}$ for coconut coir. In other studies, cane bagasse removed oil up to 19.95 grams of adsorbed oil per gram of adsorbent; whereas, coconut and sawdust waste adsorbed oil up to 6.4 $\mathrm{g} \cdot \mathrm{g}^{-1}$ [Ali et al. 2012; Annunciado et al. 2005a; Sabir 2015]. The higher adsorption capacity of bagasse in comparison with sawdust and coconut coir is explained based on its chemical structure. The chemical constitution of bagasse is characterized by its highly packed crystalline structures due to its cellulose, hemicellulose and lignin content. This compactness allows insolubility of the adsorbent in water and an increase of non-polarity affinity with oil; moreover, ad-

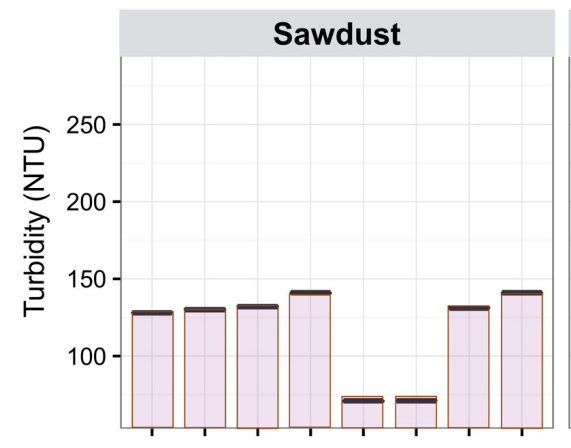

$\begin{array}{llllllll}A_{1} & A_{2} & A_{3} & A_{4} & A_{5} & A_{6} & A_{7} & A_{8}\end{array}$

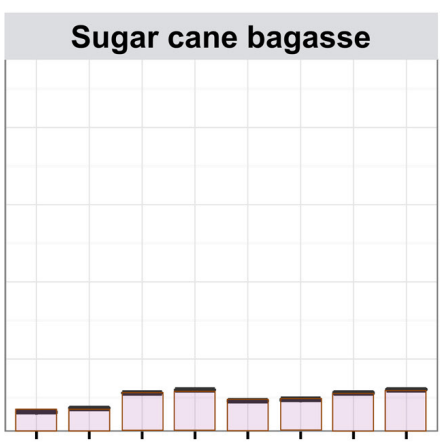

$\begin{array}{llllllll}A_{1} & A_{2} & A_{3} & A_{4} & A_{5} & A_{6} & A_{7} & A_{8}\end{array}$

Treatments

Figure 2. Treatments for the bioadsorption experiment according to CFRD - Bioadsorbents dosing concentrations and their particle sizes related to final turbidity: treatments $\left(\mathrm{A}_{1}\right) 1.0 \mathrm{~g} \cdot \mathrm{L}^{-1}$ and $0.5 \mathrm{~mm} ;\left(\mathrm{A}_{2}\right) 1.0 \mathrm{~g} \cdot \mathrm{L}^{-1}$ and $1.5 \mathrm{~mm}$; $\left(\mathrm{A}_{3}\right) 3.0 \mathrm{~g} \cdot \mathrm{L}^{-1}$ and $0.5 \mathrm{~mm} ;\left(\mathrm{A}_{4}\right) 3.0 \mathrm{~g} \cdot \mathrm{L}^{-1}$ and $1.5 \mathrm{~mm} ;\left(\mathrm{A}_{5}\right) 0.6 \mathrm{~g} \cdot \mathrm{L}^{-1}$ and $0.3 \mathrm{~mm} ;\left(\mathrm{A}_{6}\right) 0.6 \mathrm{~g} \cdot \mathrm{L}^{-1}$ and $1.5 \mathrm{~mm} ;\left(\mathrm{A}_{7}\right)$ $3.0 \mathrm{~g} \cdot \mathrm{L}^{-1}$ and $0.3 \mathrm{~mm} ;\left(\mathrm{A}_{8}\right) 3.0 \mathrm{~g} \cdot \mathrm{L}^{-1}$ and $1.5 \mathrm{~mm}$. Mean initial turbidity: $310.6 \mathrm{NTU}$ 
ditional mechanical strength is attributed to the formation of microfibrils [Mosier, 2005]. The cellulose content in sawdust is $46.4 \%$, in bagasse $32-48 \%$ and coconut coir $35.9 \%$; the content of lignin is $29.4 \%$ in sawdust, $15-32 \%$ in bagasse and $53.5 \%$ in coconut coir respectively [Israel et al. 2011; Mosier 2005; Sabir 2015; Salit 2014].

Figure 3 shows the change of turbidity according to the interaction of two factors: bioadsorbent dose and its particle mesh size. The high separating remotion of turbidity was achieved at low doses of sawdust and coir $\left(0.6 \mathrm{~g} \cdot \mathrm{L}^{-1}\right)$ and their small particle mesh sizes $(0.3 \mathrm{~mm})$; that is, a smaller bioadsorbent particle size increases the contact surface area, decreases drag forces and thus the agglomeration forces are enhanced to adsorb oil microdroplets. Bagasse, coir and sawdust showed efficient sorption effect because cellulose together with lignin and hemicellulose formed crystal structures of high surface area. It was observed that adsorption capacity diminishes without agitation; thus, in all experiments continuous agitation for $20 \mathrm{~min}$ increased mass transfer, adhesion forces and chemical affinity on dipole-dipole interactions. In all bioadsorption treatments a high dose of $3 \mathrm{~g} \cdot \mathrm{L}^{-1}$ decreased the effect of coalescing forces. Therefore, in the following treatments it was used a dose of bioadsorbent of $0.6 \mathrm{~g} \cdot \mathrm{L}^{-1}$ and particle mesh size of $0.3 \mathrm{~mm}$.

\section{Effect of coagulant dose and concentration}

The results, presented in Figure 4, show the turbidity removal effect when dosing different concentrations of $\mathrm{FeCl}_{3}$ and PAC under no bioadsorption. From initial turbidity 310.6 NTU, the turbidity removal was almost $100 \%$ when PAC was used at $5 \%$ and $\mathrm{FeCl}_{3}$ at $15 \%$. When no bioadsorbents were used, the optimal dosing concentration of PAC $5 \%$ and PA were $2.0 \mathrm{~mL} \cdot \mathrm{L}^{-1}$ and $10.0 \mathrm{~mL} \cdot \mathrm{L}^{-1}$ respectively. Colloidal destabilization using PAC was achieved because aluminum monomers formed complex ions with water molecules; consequently, hydrolysis of water molecules occurred and therefore $\mathrm{pH}$ decreased. A deprotonating effect in the aqueous media destabilized the negatively charged colloids and thus coagulation-flocculation was highly enhanced. According to Figure 4, it is remarkable that a $5 \%$ PAC solution was enough to remove colloidal contamination. This represents an important saving in chemical consumption and remediation costs. In addition, PAC was more efficient than

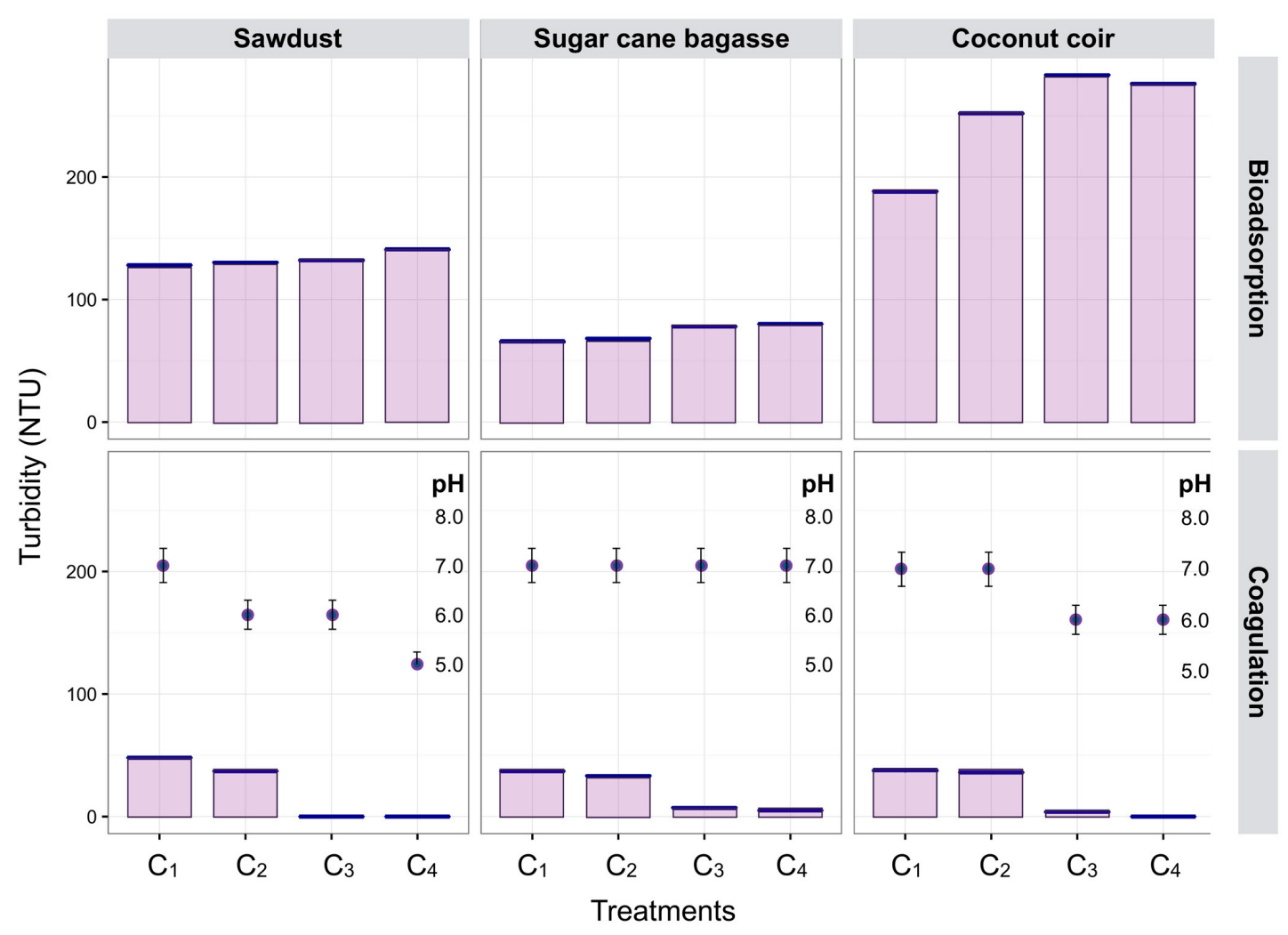

Figure 3. Mean effects plot for three levels of bioadsorbent doses and their particle mesh sizes. Bioadsorption treatments for sawdust, sugar cane bagasse and coconut coir 


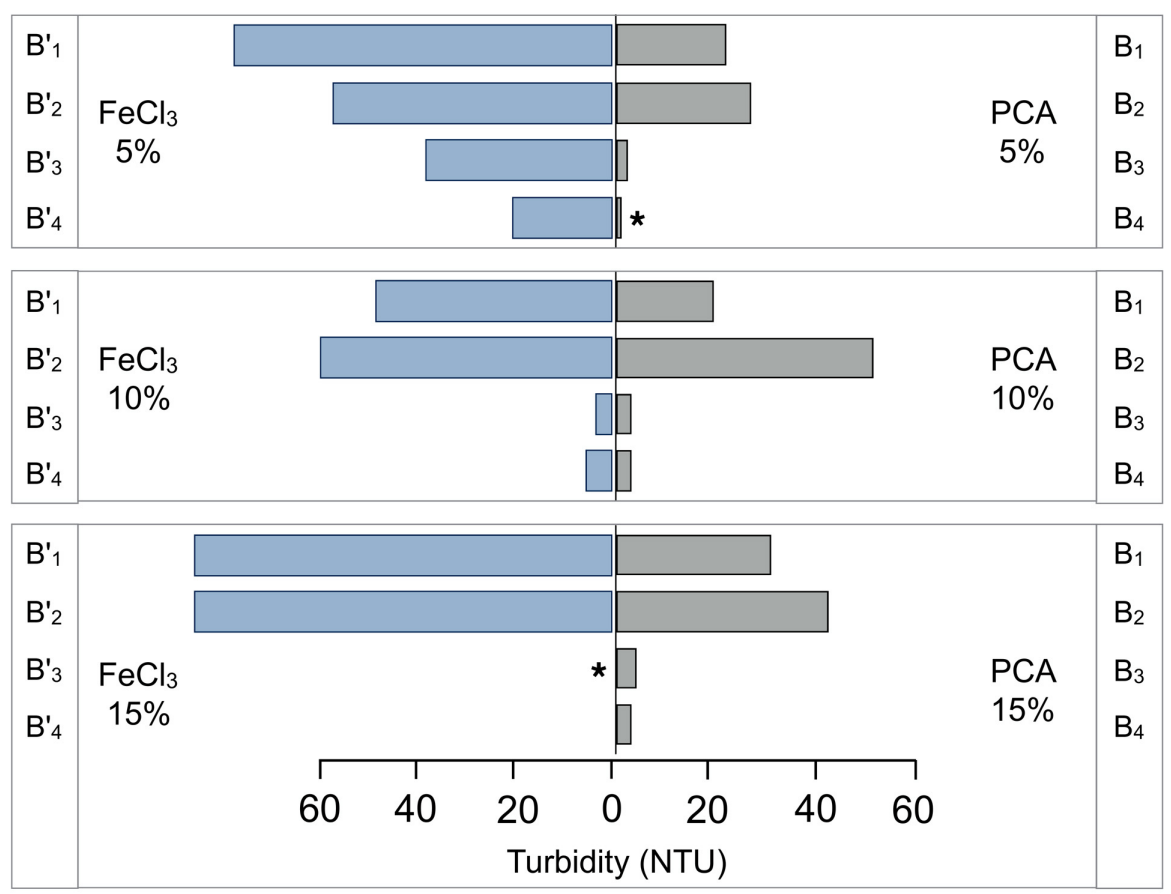

Figure 4. Comparison of two coagulants $\left(\mathrm{PAC}\right.$ and $\mathrm{FeCl}_{3}$ ) and $\mathrm{PA}$ as flocculant. Where, $\mathrm{B}$ ' represents treatments with $\mathrm{FeCl}_{3}$ and $\mathrm{B}$ with $\mathrm{PAC}$ at 5, 10 and $15 \%$. Coagulant and flocculant doses were: $\left(\mathrm{B}_{1}\right) 0.2$ and $1.0 \mathrm{~mL} \cdot \mathrm{L}^{-1} ;\left(\mathrm{B}_{2}\right)$ 0.2 and $10.0 \mathrm{~mL} \cdot \mathrm{L}^{-1} ;\left(\mathrm{B}_{3}\right) 2.0 \mathrm{~mL}$ and $1.0 \mathrm{~mL} \cdot \mathrm{L}^{-1} ;\left(\mathrm{B}_{4}\right) 2.0$ and $10.0 \mathrm{~mL} \cdot \mathrm{L}^{-1}$. Mean initial turbidity: $310.6 \mathrm{NTU}$

$\mathrm{FeCl}_{3}$ because of the wide $\mathrm{pH}$ range that $\mathrm{PAC}$ is able to perform. Therefore, $5 \%$ PAC solution was selected for further experiments.

\section{Effect of coagulation assisted by bioadsorption}

The effect of combining bioadsorption and coagulation-flocculation to remove turbidity was investigated (Fig. 5). In this experiment, the optimal bioadsorbent dosing concentration was 0.6 $\mathrm{g} \cdot \mathrm{L}^{-1}$ and mesh size was $0.3 \mathrm{~mm}$, as demonstrated before. As a result, almost $100 \%$ of turbidity was removed when the three bioadsorbents were used and when $5 \%$ PAC dose was $1.0 \mathrm{~mL} \cdot \mathrm{L}^{-1}$ and PA was 0.6 and $1.6 \mathrm{~mL} \cdot \mathrm{L}^{-1}$ respectively. Independent of the performance of the three bioadsorbents on turbidity removal (approx. 40-75\%), coagulation-flocculation removed turbidity efficiently until almost $100 \%$. A noticeable difference was the change in $\mathrm{pH}$. When using sugar cane bagasse, $\mathrm{pH}$ was reduced from 8.5 to 7.0. But sawdust and coir did not stop the acidic change of the media due to the water hydrolysis effect from PAC. In comparison with the previous treatment where no bioadsorption was used, the addition of natural sorbents enhanced the coagulation effect because the dose of chemicals were diminished. Dosing concentration of 5\% PAC was reduced from 2 to $1 \mathrm{~mL} \cdot \mathrm{L}^{-1}$ and also the dose of flocculant from 10 to $1.6 \mathrm{~mL} \cdot \mathrm{L}^{-1}$. Thus, bioadsorption with cellulosic materials tends to decrease the entropy of the emulsion which allowed separation of oil microdroplets. The adsorbant-adsorbate high non-polar affinities showed a decrease of stability forces of the former emulsion and, as consequence, the coagulation effect was increased which is demonstrated in the lower consumption of $5 \%$ PAC and PA.

\section{Effect of salinity}

This experiment tested the effect of salinity in the remediation process at 0.5 and $1.5 \%$ $\mathrm{NaCl}$ concentrations (Fig. 6). Dosing concentrations of bioadsorbents, PAC and PA were tested according to previous treatments. Results point out that both salinities concentrations enabled almost $100 \%$ turbidity removal when dosing $5 \%$ PAC $0.6 \mathrm{~mL} \cdot \mathrm{L}^{-1}$ and PA $1.6 \mathrm{~mL} \cdot \mathrm{L}^{-1}$ respectively. When wastewater was treated with coconut coir, pH changed exactly from 8.5 to 7.0. But when treated with sawdust and bagasse, $\mathrm{pH}$ was reduced to 8-6. The effect of salinity on the high removal of turbidity is explained by the increase of ionic strength due to sodium chloride. An electrolytic solution reduces the stability of the colloidal double layer. Thus, coagulation is 


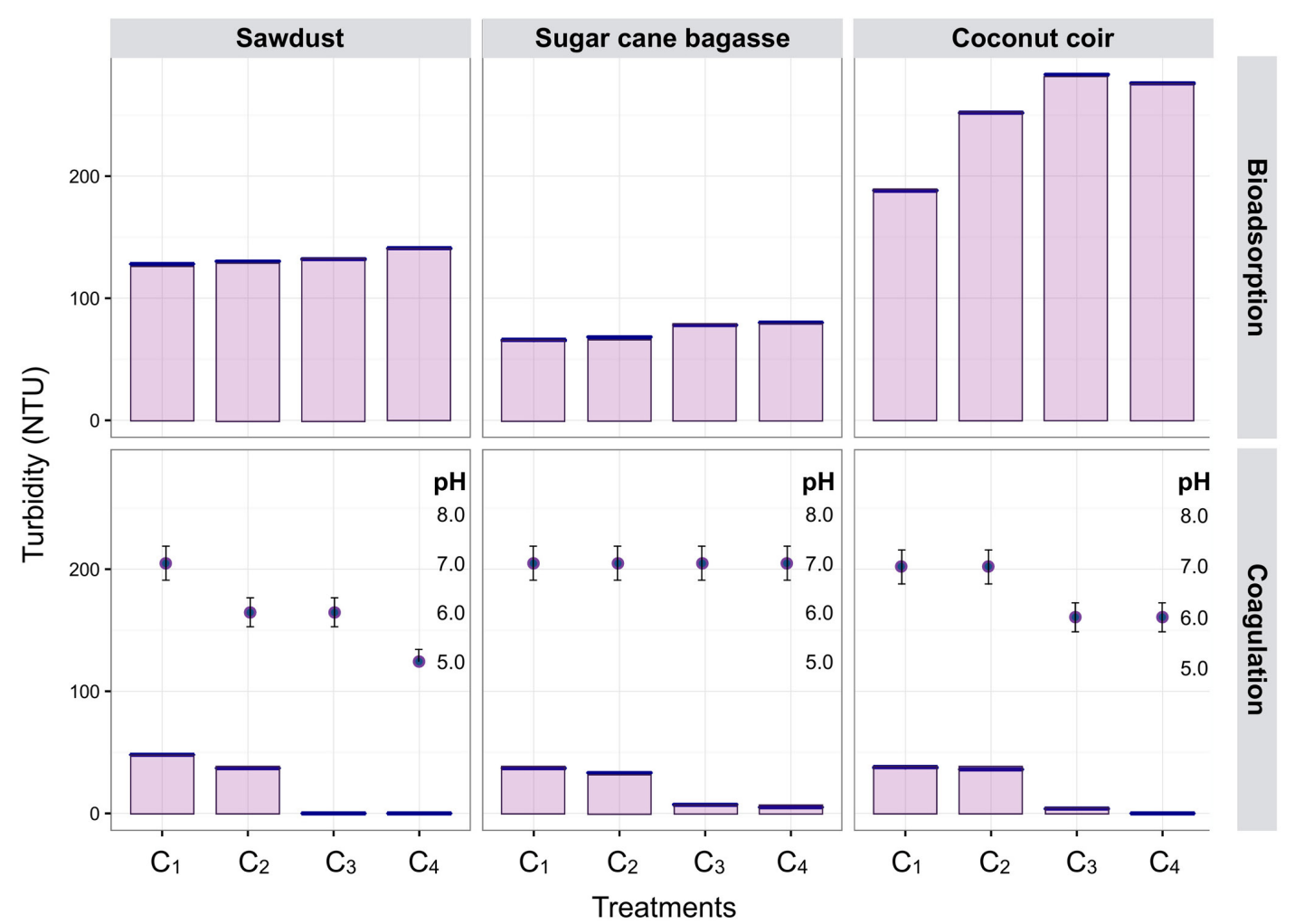

Figure 5. Effect of coagulation assisted by bioadsorption. Dosing concentrations of $5 \%$ PAC and PA: $\left(\mathrm{C}_{1}\right) 0.2$ and $0.6 \mathrm{~mL} \cdot \mathrm{L}^{-1} ;\left(\mathrm{C}_{2}\right) 0.2$ and $1.6 \mathrm{~mL} \cdot \mathrm{L}^{-1} ;\left(\mathrm{C}_{3}\right) 1.0$ and $0.6 \mathrm{~mL} \cdot \mathrm{L}^{-1} ;\left(\mathrm{C}_{4}\right) 1.0$ and $1.6 \mathrm{~mL} \cdot \mathrm{L}^{-1}$. Mean initial turbidity: 310.6 NTU

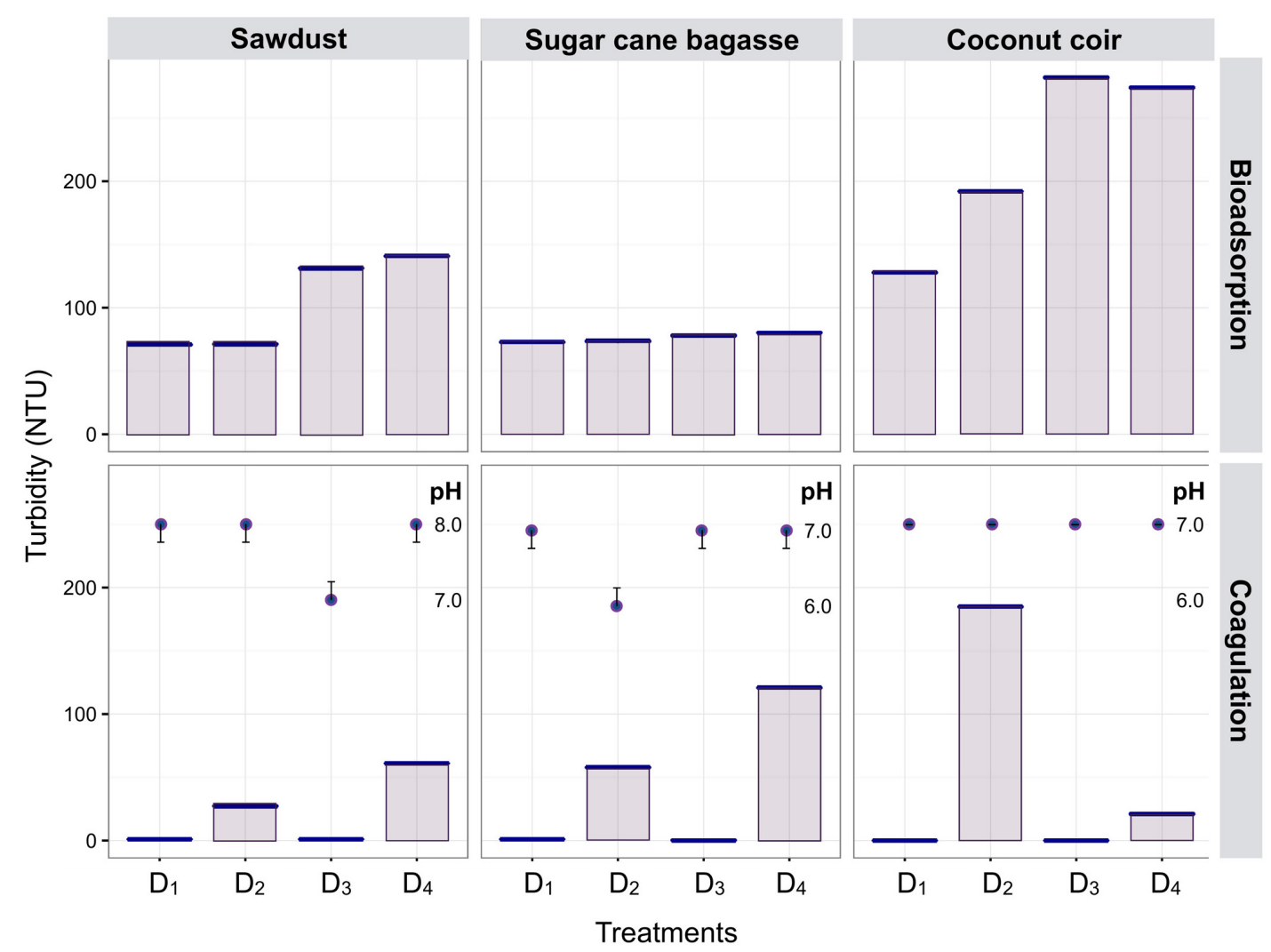

Figure 6. Turbidity and $\mathrm{pH}$ after bioadsorption and coagulation-flocculation processes under two salinity conditions. Dosing concentrations: $\left(\mathrm{D}_{1}\right) 0.5 \% \mathrm{NaCl}$ and $5 \% \mathrm{PAC} 0.6 \mathrm{~mL} \cdot \mathrm{L}^{-1} ;\left(\mathrm{D}_{2}\right) 0.5 \% \mathrm{NaCl}$ and $5 \% \mathrm{FeCl}_{3} 0.6 \mathrm{~mL} \cdot \mathrm{L}^{-1}\left(\mathrm{D}_{3}\right) 1.5 \% \mathrm{NaCl}$ and $5 \% \mathrm{PAC} 0.6 \mathrm{~mL} \cdot \mathrm{L}^{-1} ;\left(\mathrm{D}_{4}\right) 1.5 \% \mathrm{NaCl}$ and $5 \% \mathrm{FeCl}_{3} 0.6 \mathrm{~mL} \cdot \mathrm{L}^{-1}$. Flocculant dose in all treatments: $1.6 \mathrm{~mL} \cdot \mathrm{L}^{-1}$ 
improved even at low PAC dosing concentrations. The salinity effect was also tested in electrocoagulation experiments at $2 \mathrm{~g} \cdot \mathrm{L}^{-1} \mathrm{NaCl}$ and it enabled a rapid and efficient decoloration of dyes with $\mathrm{Fe}$ and $\mathrm{Al}$ electrodes [Daneshvar et al. 2003; Yang \& Mcgarrahan 2005]. According to results, the dosing concentration of PAC was also decreased in this experiment. In comparison with previous treatment, 5\% PAC dosing concentration was decreased from 1.0 to $0.6 \mathrm{~mL} \cdot \mathrm{L}^{-1}$. The influence of salinity on the emulsion clearly affected the stabilization of its electric double layer. The results demonstrate the positive effect on coagulation due to the increase of ionic strength which intertwine colloidal particles to a state of lower entropy. Because adsorption and coagulation are processes against the second law of Thermodynamics, salinity boosts the rapid destabilization of colloidal systems.

It was estimated that the automobile service station in Quito (Ecuador) annually discharges approx. $162 \mathrm{~m}^{3}$ of wastewater. Therefore, in order to remove approx. $100 \%$ of turbidity from this total effluent volume $324 \mathrm{~L}$ of $5 \%$ PAC and $1624 \mathrm{~L}$ of $0.1 \%$ PA would be needed without any adsorption process. If bioadsorption is utilized using sawdust from pine trees, sugar cane bagasse or coconut coir fibers, then to remove approx. $100 \%$ of turbidity from $162 \mathrm{~m}^{3}$ of wastewater $97.2 \mathrm{~L}$ of $5 \%$ PAC and $260 \mathrm{~L}$ of $0.1 \%$ PA would be needed annually. Therefore, it is clear that a cost saving per year of almost $70 \%$ is achieved when using these bioadsorbents under $1.5 \% \mathrm{NaCl}$ concentration.
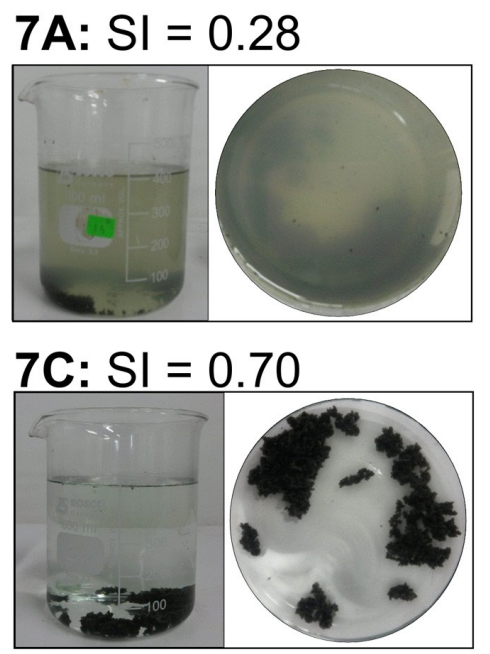

Another advantage that saline conditions offered in this remediation process is related with the mechanical stability of the sludge which was positively affected (Fig. 7). From Figure $7 \mathrm{~A}$ to $7 \mathrm{D}$, the pictures show that sedimented particles are more compact and agglomerated where saline conditions were applied. In contrast, the treatments without salinity led to blurry and dispersed sediments without strong consistency. Sludge index have a direct impact on the efficiency of waste management in a treatment plant.

\section{Quality of treated water}

Under the best remediation conditions a characterization of water is presented in Table 3. In this characterization, coconut coir was chosen as bioadsorbent because it enabled a treatment stabilization until $\mathrm{pH}$ 7. According to results, one gram of coir adsorbed $2.1 \mathrm{~g}$ of oil. It represented $98 \%$ of oil remotion. According to other authors, one gram of sugar cane bagasse and coconut coir could adsorb between 5.4 and $19.95 \mathrm{~g}$ of oily substances [Annunciado et al. 2005b; Sabir 2015]. In the present work, after coagulation, oils were removed until approx. $99.9 \%$. In terms of heavy metals, the adsorption capacity of coconut coir was $41 \mathrm{mg} \cdot \mathrm{g}^{-1}$ for aluminum, $0.73 \mathrm{mg} \cdot \mathrm{g}^{-1}$ for lead, $1.35 \mathrm{mg} \cdot \mathrm{g}^{-1}$ for copper and $0.22 \mathrm{mg} \cdot \mathrm{g}^{-1}$ for chromium respectively. In the present work, natural sorbents without chemical treatment were used; in contrast, literature reports adsorption capac-
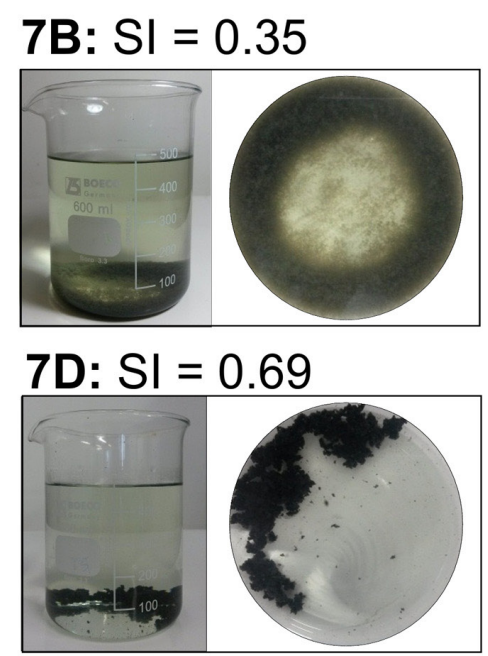

Figure 7. Effect of salinity on sludge index. Treatments without salinity: (A) $5 \% \mathrm{PAC} 0.6 \mathrm{~mL} \cdot \mathrm{L}^{-1}$, (B) $5 \%$ PAC $1.0 \mathrm{~mL} \cdot \mathrm{L}^{-1}$. Treatments with $1.5 \% \mathrm{NaCl}$ : (C) $5 \%$ PAC $0.6 \mathrm{~mL} \cdot \mathrm{L}^{-1}$, (D) $5 \%$ PAC $1.0 \mathrm{~mL} \cdot \mathrm{L}^{-1}$. Flocculant dose in all treatments: $1.6 \mathrm{~mL} \cdot \mathrm{L}^{-1}$ 
Table 3. Characterization of water before and after treatments

\begin{tabular}{|l|c|c|c|}
\hline \multicolumn{1}{|c|}{ Parameters } & Wastewater & After bioadsorption & After coagulation \\
\hline Oil and grease, $\mathrm{mg} \cdot \mathrm{L}^{-1}$ & 1286.0 & 26.4 & 0.5 \\
\hline Aluminum, $\mathrm{mg} \cdot \mathrm{L}^{-1}$ & 25.69 & 1.09 & 0.12 \\
\hline Lead, $\mathrm{mg} \cdot \mathrm{L}^{-1}$ & 0.54 & 0.1 & 0.09 \\
\hline Copper, $\mathrm{mg} \cdot \mathrm{L}^{-1}$ & 0.83 & 0.02 & 0.002 \\
\hline Chromium, $\mathrm{mg} \cdot \mathrm{L}^{-1}$ & 0.14 & 0.01 & 0.006 \\
\hline $\mathrm{BOD}$ & $\mathrm{mg} \mathrm{O} \cdot \mathrm{L}^{-1}$ & 80.0 & 10.0 \\
\hline $\mathrm{COD}, \mathrm{mg} \mathrm{O} \cdot \mathrm{L}^{-1}$ & 200.0 & 244.0 & 33.0 \\
\hline $\mathrm{pH}$ & 816.0 & 7.7 & 7.0 \\
\hline $\mathrm{EC}, \mu \mathrm{s} \cdot \mathrm{cm}^{-1}$ & 8.5 & 13.2 & 9.2 \\
\hline Turbidity, NTU & 496.0 & 64.0 & 0.0 \\
\hline TDS, $\mathrm{mg} \cdot \mathrm{L}^{-1}$ & 310.6 & 32.9 & 1.1 \\
\hline $\mathrm{SS}, \mathrm{mg} \cdot \mathrm{L}^{-1}$ & 50.6 & 95.0 & 2.0 \\
\hline AT, $\mathrm{mg} \cdot \mathrm{L}^{-1}$ & 260.5 & 3.03 & 0.23 \\
\hline $\mathrm{CT}, \mathrm{mg} \cdot \mathrm{L}^{-1}$ & 6.63 & 0.27 & 0.03 \\
\hline $\mathrm{NIT}, \mathrm{mg} \cdot \mathrm{L}^{-1}$ & 0.76 & 0.30 & 0.0 \\
\hline
\end{tabular}

8A

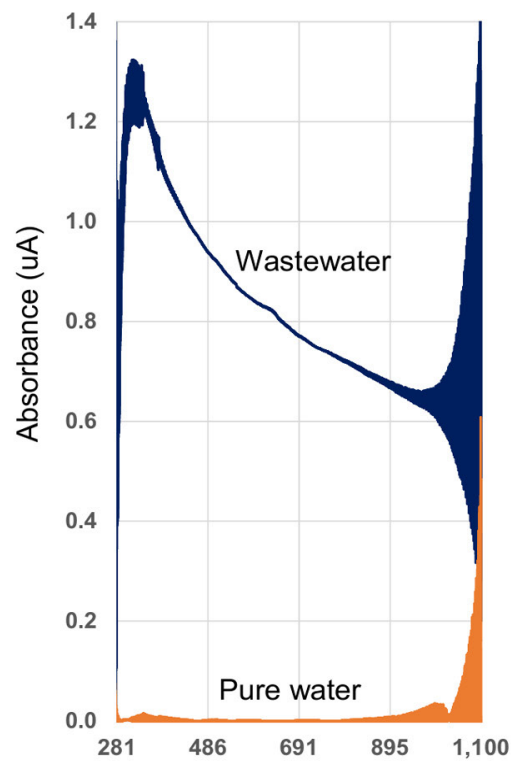

8B

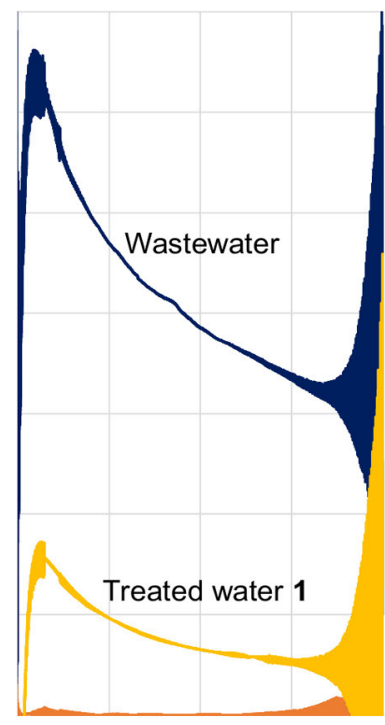

Wavelength $(\mathrm{nm})$
8C

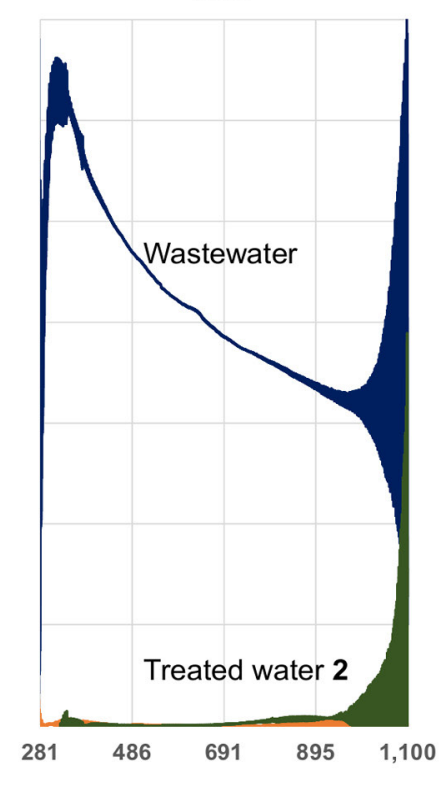

Figure 8. UV-VIS spectra between 280 and $1100 \mathrm{~nm}$ of (A) wastewater and pure water, (B) wastewater and treated water using coconut coir and $(\mathrm{C})$ wastewater and treated water using bioadsorption-coagulation-flocculation

ity of $263 \mathrm{mg} \cdot \mathrm{g}^{-1}$ for lead and $11.56 \mathrm{mg} \cdot \mathrm{g}^{-1}$ for chromium when using chemically modified coconut coir as activated carbons under acidic pH [Bhatnagar \& Sillanpää 2010]. In general, adsorption and coagulation processes are used to remove colloidal contamination but in some cases dissolved pollutants get adsorbed thus reducing its content in terms of dissolved matter. In this work, dissolved contamination (BOD, COD, AT, CT, NIT and TDS) were removed approx. up to $97.8 \%$.
The UV-VIS spectra of water samples before and after every treatment were taken from 280 to $1100 \mathrm{~nm}$ (Fig. 8) in order to confirm the remotion of colloidal particles. The wastewater sample shows peak responses regarding its content of hydrocarbon and tensoactive substances. These peaks are shifted toward the long wavelength region in the visible region (400 to 1100 $\mathrm{nm})$. The responses in the visible region are also a function of the particle size; thus, they tend to disappear in treated samples. 


\section{CONCLUSIONS}

Wastewater from automobile service stations is generally oily and highly turbid; additionally, it is considered an emulsion system because of its tensoactive content interacts with oily compounds. Therefore, adsorption using natural sorbents and chemical coagulation was used to remove colloidal particles. The interaction of both processes enabled almost a $100 \%$ efficiency to precipitate solids. Also, dissolved particles including heavy metals were removed up to $97.8 \%$ because coagulation-flocculation processes were boosted by bioadsorption and ionic strength. Small particle sizes and low doses of sawdust from pine trees, sugar cane bagasse and coconut coir fibers were used without any chemical modification as bioadsorbents based on their non-polar affinity to oily pollutants. An increase in the ionic strength due to $\mathrm{NaCl}$ addition positively affected the remediation process. The bioadsorption process and the saline aqueous media reduced the consumption of aluminum and polyacrylamide up to $70 \%$. Another benefit from the chemical interaction herein studied was the increase of the mechanical cohesion of sediments, namely a high sludge index was achieved. A saving in the consumption of chemicals and formation of a compact sludge lead to improve the features of waste management. Although more research is needed to environmentally dispose oily-loaded sorbents and sludge, the present work offers an ecofriendly solution to save operational costs in a wastewater treatment plant without compromising efficiency.

\section{Acknowledgements}

The authors thank Lab specialists Xavier Alava and Pavlova Sigcha from UDLA for their assistance in all experiments.

\section{REFERENCES}

1. Abdeen, Z., \& Moustafa, Y.M.M. 2016. Treatment of Oily Wastewater by Using Porous PVA Hydrogels as Oil Adsorbent. Journal of Dispersion Science and Technology, 37(6), 799-805. DOI: 10.1080/01932691.2015.1062774.

2. Abdel Salam, O.E., Reiad, N.A., \& ElShafei, M.M. 2011. A study of the removal characteristics of heavy metals from wastewater by low-cost adsorbents. Journal of Advanced Research, 2(4), 297303. DOI: 10.1016/j.jare.2011.01.008.
3. Abdelmoez, W., Barakat, N.A.M., \& Moaz, A. 2013. Treatment of wastewater contaminated with detergents and mineral oils using effective and scalable technology. Water Science \& Technology, 68(5), 974. DOI: 10.2166/wst.2013.275.

4. Ali, N., El-Harbawi, M., Jabal, A.A., \& Yin, C.Y. 2012. Characteristics and oil sorption effectiveness of kapok fibre, sugarcane bagasse and rice husks: oil removal suitability matrix. Environmental Technology, 33(4), 481-486. DOI: 10.1080/09593330.2011.579185.

5. Annunciado, T.R., Sydenstricker, T.H.D., \& Amico, S.C. 2005a. Experimental investigation of various vegetable fibers as sorbent materials for oil spills. Marine Pollution Bulletin, 50(11), 13401346. DOI: 10.1016/j.marpolbul.2005.04.043.

6. Annunciado, T.R., Sydenstricker, T.H.D., \& Amico, S.C. 2005b. Experimental investigation of various vegetable fibers as sorbent materials for oil spills. Marine Pollution Bulletin, 50(11), 13401346. DOI: 10.1016/j.marpolbul.2005.04.043.

7. Barakat, M.A. 2011. New trends in removing heavy metals from industrial wastewater. Arabian Journal of Chemistry, 4(4), 361-377. DOI: 10.1016/j.arabjc.2010.07.019.

8. Bhatnagar, A., \& Sillanpää, M. 2010a. Utilization of agro-industrial and municipal waste materials as potential adsorbents for water treatment-A review. Chemical Engineering Journal, 157(2-3), 277-296. DOI: 10.1016/j.cej.2010.01.007.

9. Bhatnagar, A., \& Sillanpää, M. 2010b. Utilization of agro-industrial and municipal waste materials as potential adsorbents for water treatment-A review. Chemical Engineering Journal, 157(2-3), 277-296. DOI: 10.1016/j.cej.2010.01.007.

10. Daneshvar, N., Ashassi-Sorkhabi, H., \& Tizpar, A. 2003. Decolorization of orange II by electrocoagulation method. Separation and Purification Technology, 31(2), 153-162.

11. Israel, A.U., Ogali, R.E., Akaranta, O., \& Obot, I.B. 2011. Extraction and characterization of coconut (Cocos nucifera L.) coir dust. Songklanakarin Journal Science Technology, 33(6), 717-724.

12. Kumar, S.A., Kokila, A., \& Banu, J.R. 2014. Biodegradation of automobile service station wastewater. Desalination and Water Treatment, 52(25-27), 4649-4655. DOI: 10.1080/19443994.2013.808416.

13. Lau, W.J., Ismail, A.F., \& Firdaus, S. 2013. Car wash industry in Malaysia: Treatment of car wash effluent using ultrafiltration and nanofiltration membranes. Separation and Purification Technology, 104, 26-31. DOI: 10.1016/j.seppur.2012.11.012.

14. Mohamed, R., Saphira, R.M., Kutty, A.I., Mariam, N., Kassim, M., \& Hashim, A. 2014. Efficiency of using commercial and natural coagulants in treating 
car wash wastewater treatment. Australian Journal of Basic and Applied Sciences, 8(16), 227-234.

15. Mosier, N. 2005. Features of promising technologies for pretreatment of lignocellulosic biomass. Bioresource Technology, 96(6), 673-686. DOI: 10.1016/j.biortech.2004.06.025.

16. OICA. 2016. World Motor Vehicle Sales. International Organization of Motor Vehicle Manufacturers. Retrieved from http://www.oica.net/wp-content/uploads//total-sales-20151.pdf.

17. Sabir, S. 2015. Approach of Cost-Effective Adsorbents for Oil Removal from Oily Water. Critical Reviews in Environmental Science and Technology, 45(17), 1916-1945. DOI: $0.1080 / 10643389.2014 .1001143$.

18. Salit, M.S. 2014. Tropical Natural Fibres and Their Properties. In: M.S. Salit, Tropical Natural Fibre Composites, pp. 15-38. Singapore: Springer Singapore. Retrieved from DOI: 10.1007/978-981-287-155-8_2.

19. Shadizadeh, S.R., Khodashenas, A., Abtahi, S.M.,
\& Roayaei, E. 2014. Experimental Investigation of Oil Spill Cleanup Using Cholan as a Natural Oil Absorber. Energy Sources, Part A: Recovery, Utilization, and Environmental Effects, 36(9), 982-992. DOI: $10.1080 / 15567036.2010 .549924$.

20. Sokolovic, S., Secerov-Sokolovic, R., \& Putnik, S. 1992. Some aspects of application of waste polymer materials as a coalescence medium for oily wastewater treatment. Environmental Technology, 13(10), 987-994. DOI: 10.1080/09593339209385234.

21. Yang, C., \& Mcgarrahan, J. 2005. Electrochemical coagulation for textile effluent decolorization. Journal of Hazardous Materials, 127(1-3), 40-47. DOI: 10.1016/j.jhazmat.2005.05.050.

22. Zhao, S., Huang, G., Fu, H., \& Wang, Y. 2014. Enhanced Coagulation/Flocculation by Combining Diatomite with Synthetic Polymers for Oily Wastewater Treatment. Separation Science and Technology, 49(7), 999-1007. DOI: $10.1080 / 01496395.2013 .877035$. 